\title{
Fracionamento de carboidratos e compostos nitrogenados de genótipos de capim-elefante aos 56 dias de rebrota ${ }^{1}$
}

\section{Erico da Silva Lima ${ }^{2}$, José Fernando Coelho da Silva ${ }^{3}$, Hernán Maldonado Vásquez ${ }^{3}$, Saulo Alberto do Carmo Araújo ${ }^{2}$, Tiago Cunha Rocha ${ }^{4}$, Dorival Pereira Borges da Costa ${ }^{5}$}

\footnotetext{
1 Pesquisa financiada pela FAPERJ.

2 Programa de Pós-graduação em Produção Animal da UENF-CCTA-LZNA, Av. Alberto Lamego, 2000, Horto, CEP: 28015-620, Campos dos Goytacazes, Rio de Janeiro.

3 UENF-CCTA-LZNA, Av. Alberto Lamego, 2000, Horto, CEP: 28015-620, Campos dos Goytacazes, Rio de Janeiro. Pesquisador do CNPq.

${ }^{4}$ Curso de Graduação em Zootecnia da UENF-CCTA-LZNA, Av. Alberto Lamego, 2000, Horto, CEP: 28015-620, Campos dos Goytacazes, Rio de Janeiro.

${ }^{5}$ Doutorando do Programa de Pós-graduação em Zootecnia - UNESP/FMVZ/Botucatu.
}

RESUMO - Objetivou-se neste estudo determinar as frações de carboidratos e de compostos nitrogenados de genótipos de capim-elefante, em um único corte aos 56 dias de idade, na primavera. Avaliaram-se 12 genótipos de capim-elefante em um delineamento de blocos ao acaso com três repetições, no qual a parcela experimental foi composta de quatro linhas com $3 \mathrm{~m}$ de comprimento, espaçadas $1 \mathrm{~m}$ e adubadas com $100 \mathrm{~kg}$ de $\mathrm{P}_{2} \mathrm{O}_{5}, 100 \mathrm{~kg}$ de N, $60 \mathrm{~kg}$ de $\mathrm{K}_{2} \mathrm{O}$ e $25 \mathrm{~kg}$ de micronutrientes/ha As frações de carboidratos $\mathrm{A}+\mathrm{B}_{1}, \mathrm{~B}_{2}$ e $\mathrm{C}$ diferiram entre os genótipos. Os genótipos CNPGL 92-94-01, CNPGL 92-70-02, CNPGL 91-06-02, CNPGL 91-25-01, CNPGL 93-32-02 e Cameroon apresentaram os menores valores da fração C de carboidratos. Entre as frações nitrogenadas, apenas as frações $\mathrm{B}_{3}$ e $\mathrm{C}$ apresentaram diferenças. Os menores valores da fração C nitrogenada foram observados nos genótipos CNPGL 92-70-02, Napier, CNPGL 94-07-02 e CNPGL 91-25-01.

Palavras-chave: cultivares de capim-elefante, carboidratos, frações nitrogenadas, híbridos intra-específicos

\section{Carbohydrates and nitrogen compounds fractions of elephant grass genotypes at 56 days of regrowth}

\begin{abstract}
The objective of this study was to determine carbohydrates and nitrogen compounds fractions of genotypes of elephant grass in a single cut at 56 days of regrowth, in the spring season. Twelve elephant grass genotypes were evaluated in a in randomized block design with three replications, in which the experimental plot consisted of four lines with $3 \mathrm{~m}$ length, spaced $1 \mathrm{~m}$ and fertilized with $100 \mathrm{~kg}$ of $\mathrm{P}_{2} \mathrm{O}_{5}, 100 \mathrm{~kg}$ of N, $60 \mathrm{~kg} \mathrm{~K} 2 \mathrm{O}$ and $25 \mathrm{~kg}$ of micronutrients/ha. Carbohydrates fractions $\mathrm{A}+\mathrm{B}_{1}, \mathrm{~B}_{2}$ and $\mathrm{C}$ differed among genotypes. The genotypes CNPGL 92-94-01, 92-70-02 CNPGL, CNPGL 91-06-02, CNPGL 91-25-01, 93-32-02 CNPGL and Cameroon showed the lowest values of carbohydrates $\mathrm{C}$ fraction. Among the nitrogen compounds fractions, only B3 and C fractions showed differences. The lowest values of nitrogen compounds $\mathrm{C}$ fraction were observed in genotypes CNPGL 92-70-02, Napier, CNPGL CNPGL 94-07-02 and 91-25-01.
\end{abstract}

Key Words: carbohydrates, cultivars of elephant grass, intra-specific hybrids, nitrogen fractions

\section{Introdução}

No Brasil, as gramíneas possuem grande importância, pois são a base da alimentação dos animais dos rebanhos leiteiros e de corte. Entre as espécies utilizadas na alimentação de ruminantes, o capim-elefante (Pennisetum purpureum, Schum.) se destaca, pois é reconhecidamente uma forrageira perene, de alto potencial de produção de matéria seca e alto valor nutricional. Entretanto, necessita de condições climáticas adequadas e solo fértil para produção satisfatória.
O capim-elefante tem sido muito utilizado por produtores rurais, principalmente os da pecuária leiteira, que trabalham com margem de lucro pequena. Assim, é de grande importância a avaliação nutricional do capim-elefante para obtenção de genótipos que se destaquem e permitam melhor relação custo/benefício.

Os alimentos utilizados para ruminantes devem ser avaliados segundo suas frações de constituintes para sua adequada utilização (Sniffen et al., 1992). Os carboidratos totais nos alimentos podem ser divididos nas seguintes frações: A, fração solúvel do nutriente, formada de açúcares 
simples e ácidos orgânicos de rápida degradação ruminal; $\mathrm{B}_{1}$, constituída basicamente de amido e pectina e de degradação intermediária; $\mathrm{B}_{2}$, caracteriza-se por taxa de degradação ruminal mais lenta e que corresponde à porção digestível da parede celular vegetal; e C, porção da parede celular vegetal que não é digerida no trato gastrintestinal. A proteína bruta $(\mathrm{PB})$ pode ser subdividida nas seguintes frações: A, constituída basicamente por compostos nitrogenados não-protéicos (NNP), aminoácidos e peptídeos, de degradação instantânea; $B_{1}$, fração de proteínas solúveis e de rápida degradação ruminal; $\mathrm{B}_{2}$ e $\mathrm{B}_{3}$, fração de proteínas insolúveis com taxas de degradação intermediária e lenta no rúmen, respectivamente; e $\mathrm{C}$, representada por proteínas insolúveis e não-digeríveis no rúmen e nos intestinos.

Com a finalidade de determinar genótipos promissores na condição do norte-fluminense, foram avaliadas neste trabalho as frações de carboidratos e compostos nitrogenados de capim-elefante submetido a um corte aos 56 dias de idade na estação da primavera.

\section{Material e Métodos}

O experimento foi conduzido no campo experimental do Setor de Forragicultura e Nutrição de Ruminantes, do Laboratório de Zootecnia e Nutrição Animal do Centro de Ciências e Tecnologias Agropecuárias da Universidade Estadual do Norte Fluminense, Campus Darcy Ribeiro, município de Campos dos Goytacazes. O município está situado a $21^{\circ} 44^{\prime} 47^{\prime \prime}$ de latitude Sul, $41^{\circ} 18^{\prime} 24^{\prime \prime}$ de longitude Oeste e altitude de $11 \mathrm{~m}$ do nível do mar, região fisiográfica do norte do estado do Rio de Janeiro. O solo na área experimental é classificado como Latossolo Amarelo, Distrófico típico (EMBRAPA, 2006). A acidez do solo, cuja análise química encontra-se na Tabela 1 , foi corrigida com a aplicação de $1 \mathrm{t} /$ ha de calcário dolomítico PRNT 80\% (com base em 60\% da saturação de bases).

Conforme o sistema de classificação de Koppen (1948), citado por Ometto (1981), o clima da região norte-fluminense é do tipo Aw, tropical quente e úmido, com período seco no inverno e chuvoso no verão e precipitação anual em torno de $1.020 \mathrm{~mm}$. A precipitação pluviométrica durante os períodos pré-experimental (março a setembro), compreendido do plantio ao corte de uniformização, e experimental (setembro a novembro), foi de $834,20 \mathrm{~mm}$ e a temperatura média, de $22,5^{\circ} \mathrm{C}$, com médias das máximas de $28,1^{\circ} \mathrm{C}$ e médias das mínimas de $18,7^{\circ} \mathrm{C}$ (Dados obtidos na Estação Meteorológica da PESAGRO-Rio) (Figura 1).

Foram avaliados 10 novos genótipos (híbridos intraespecíficos) de capim-elefante (Pennisetum purpureum, Schum.): CNPGL 91-25-01, CNPGL 94-09-01, CNPGL 91-0602, CNPGL 94-07-02, CNPGL 92-70-02, CNPGL 92-79-02, CNPGL 93-32-02, CNPGL 94-49-06, CNPGL 92-94-01 eBAG 66 , obtidos pelo programa de melhoramento genético de forrageiras da EMBRAPA Gado de Leite, e os cultivares de capim-elefante Napier e Cameroon.

O delineamento experimental adotado foi o de blocos casualizados, com três repetições. A parcela experimental foi composta por quatro linhas de $3 \mathrm{~m}$ de comprimento, espaçadas $1 \mathrm{~m}$ entre si (parcelas de $4 \times 3$ ).

A adubação para estabelecimento foi realizada em 19/3/2005, sobre os sulcos de plantio, com $\mathrm{P}_{2} \mathrm{O}_{5}$ (superfosfato simples), $100 \mathrm{~kg} / \mathrm{ha}$, e micronutrientes (FTE), $25 \mathrm{~kg} / \mathrm{ha}$. Por ocasião do plantio, realizou-se irrigação durante as primeiras semanas de rebrota.

Em 16/9/2005, realizou-se o corte de uniformização, seguido da adubação de cobertura com nitrogênio $(100 \mathrm{~kg} / \mathrm{ha})$ e $\mathrm{K}_{2} \mathrm{O}(60 \mathrm{~kg} / \mathrm{ha})$. A área útil colhida $\left(1 \mathrm{~m}^{2}\right)$ incluiu as duas fileiras centrais, eliminando-se $1 \mathrm{~m}$ em cada extremidade

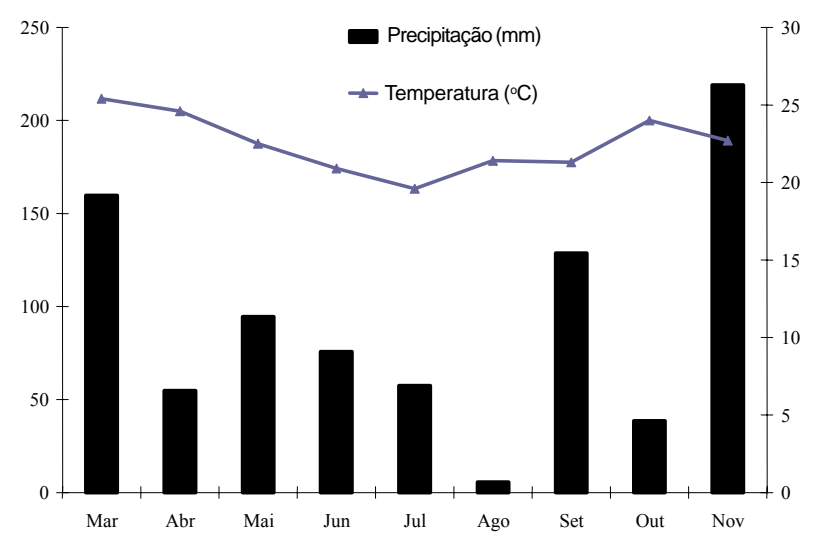

Figura 1 - Dados meteorológicos de Campos dos GoytacazesRJ durante os períodos pré-experimental e experimental.

Tabela 1 - Resultado da análise do solo da área experimental

\begin{tabular}{lccccccc}
\hline Profundidade $(\mathrm{cm})$ & $\mathrm{pH}$ & $\mathrm{P}$ & $\mathrm{K}$ & $\mathrm{Ca}+\mathrm{Mg}$ & $\mathrm{Al}$ & $\mathrm{MO}(\%)$ \\
\hline & & & $\mathrm{mg} / \mathrm{dm}^{3}$ & & & $\mathrm{cmol}_{\mathrm{c}} / \mathrm{dm}^{3}$ & \\
$0-20$ & 5,5 & 4 & & 36 & 2,2 & 0,2 & 1,72 \\
\hline
\end{tabular}

$\mathrm{MO}=$ matéria orgânica. 
(bordadura) e amostrando-se aproximadamente $500 \mathrm{~g}$, a $30 \mathrm{~cm}$ do solo, quando as forrageiras atingiram 56 dias após corte de uniformização. Um único corte foi realizado no dia 11/11/2005 para coleta das amostras.

As amostras das forrageiras foram pesadas e encaminhadas para pré-secagem a $55^{\circ} \mathrm{C}$. Depois de secas, as amostras foram pesadas novamente, trituradas em moinho com peneiras de crivos de $1 \mathrm{~mm}$ e acondicionadas em recipiente hermeticamente fechado. As análises para determinação dos teores de matéria seca (MS), matéria orgânica (MO), matéria mineral (MM), proteína bruta $(\mathrm{PB})$ e extrato etéreo (EE) foram realizadas segundo AOAC (1990); e, para determinação dos teores de fibra insolúvel em detergente neutro (FDN), fibra insolúvel em detergente ácido (FDA) e lignina Klason, segundo Van Soest \& Robertson (1985). As concentrações de nitrogênio insolúvel em detergente neutro (NIDN) e nitrogênio insolúvel em detergente ácido (NIDA) foram analisadas segundo metodologias descritas por Sniffen et al. (1992).

As concentrações de proteína insolúvel em detergente neutro (PIDN) e detergente ácido (PIDA) foram obtidas pela multiplicação dos valores de NIDN e NIDA por 6,25 e a FDNcp correspondeu ao teor de parede celular vegetal isenta de cinzas e proteínas. Os carboidratos totais (CT) foram obtidos subtraindo-se da MS os teores de proteína bruta (PB), extrato etéreo (EE) e matéria mineral (MM).

A fração $\mathrm{C}$ dos carboidratos foi obtida pela equação abaixo, descrita por Sniffen et al. (1992): C $=100 \times$ FDN $(\% \mathrm{MS}) \times 0,01 \times($ lignina $(\% \mathrm{FDN}) \times 2,4) / \mathrm{CT}(\% \mathrm{MS})$.

A expressão a seguir foi empregada no cálculo da fração $\mathrm{B}_{2}$ :

$\mathrm{B}_{2}=100 \times((\mathrm{FDN}(\% \mathrm{MS})-\mathrm{PIDN}(\% \mathrm{~PB}) \times 0,01 \times$ $\mathrm{PB}(\% \mathrm{MS}))-\mathrm{FDN}(\% \mathrm{MS}) \times 0,01 \times$ lignina $(\% \mathrm{FDN}) \times 2,4)) /$ CT (\%MS) (Sniffen et al., 1992).

As frações de carboidratos com elevadas taxas de degradação ruminal $\left(\mathrm{A}+\mathrm{B}_{1}\right)$ foram determinadas pela diferença entre 100 - (fração $\mathrm{C}+\mathrm{B}_{2}$ ). A fração $\mathrm{A}+\mathrm{B}_{1}$, considerada carboidratos não-fibrosos (CNF), foi obtida pela fórmula $\mathrm{CNF}=\mathrm{MO}-(\mathrm{PB}+\mathrm{EE}+\mathrm{FDNcp})$, em que FDNcp constitui a parede celular vegetal isenta de cinzas e proteínas.

A fração A dos compostos nitrogenados foi obtida pelo tratamento da amostra $(0,5 \mathrm{~g})$ com $50 \mathrm{~mL}$ de água destilada por 30 minutos e pela adição de $10 \mathrm{~mL}$ de ácido tricloroacético (TCA) a $10 \%$ por mais 30 minutos (Krishnamoorthy et al., 1982). Seqüencialmente, filtrou-se o conteúdo em papel-filtro (Whatman 54) e determinou-se o nitrogênio residual. A diferença entre o nitrogênio total e o nitrogênio residual foi considerada fração $A$.

A determinação do nitrogênio solúvel total foi realizada incubando-se a amostra $(0,5 \mathrm{~g})$ com $50 \mathrm{~mL}$ do tampão borato-fosfato $\left(\mathrm{NaH}_{2} \mathrm{PO}_{4} \cdot \mathrm{H}_{2} \mathrm{O}\right.$ a $12,2 \mathrm{~g} / \mathrm{L}$ de álcool butílico terciário) e $1 \mathrm{~mL}$ da solução de azida sódica a 10\%. Após 3 horas de incubação, filtrou-se a amostra residual em papelfiltro e realizou-se a análise do nitrogênio residual insolúvel no tampão borato-fosfato (TBF). O nitrogênio solúvel total (NNP + proteína solúvel + peptídeos) foi obtido pela diferença do nitrogênio total menos o nitrogênio insolúvel no TBF (Sniffen et al., 1992). A fração correspondente às proteínas solúveis $\left(\mathrm{B}_{1}\right)$ foi determinada pela diferença entre a fração nitrogênio solúvel total menos a fração NNP determinada pelo ácido tricloroacético.

Utilizando-se a diferença entre o nitrogênio insolúvel em detergente neutro (NIDN) e o nitrogênio insolúvel em detergente ácido (NIDA), determinou-se a fração $\mathrm{B}_{3}$ (Sniffen et al., 1992). A fração C foi determinada pelo NIDA (Licitra et al., 1996) e a $B_{2}$, pela diferença entre a fração insolúvel em tampão borato-fosfato e a fração NIDN (Sniffen et al., 1992).

Os resultados do fracionamento de carboidratos e compostos nitrogenados foram submetidos à análise de variância pelo Sistema de Análises Estatísticas, SISVAR (Ferreira, 1999), aplicando-se o teste Scott-Knott para verificar as diferenças entre os genótipos. As variáveis foram analisadas de acordo com o seguinte modelo:

$$
\mathrm{Y}_{\mathrm{ijk}}=\mu+\mathrm{T}_{\mathrm{i}}+\mathrm{B}_{\mathrm{j}}+\mathrm{e}_{\mathrm{ijk}}
$$

em que: $Y_{i j k}=$ resposta experimental medida sob o genótipo $\mathrm{i}$, na repetição $\mathrm{k}$ do bloco $\mathrm{j} ; \mu=$ efeito da média; $\mathrm{T}_{\mathrm{i}}=$ efeito relativo ao genótipo $\mathrm{i}, \mathrm{i}=1 ; 2 ; \ldots 12 ; \mathrm{B}_{\mathrm{j}}=$ efeito relativo ao bloco $\mathrm{j}, \mathrm{j}=1 ; 2 ; 3 ; \mathrm{e}_{\mathrm{ijk}}=$ erro aleatório.

\section{Resultados e Discussão}

A fração $\mathrm{A}+\mathrm{B}_{1}$ dos carboidratos totais diferiu $(\mathrm{P}<0,05)$ entre os genótipos (Tabela 2) e, nos genótipos CNPGL 92-79-02,CNPGL92-70-02,CNPGL91-06-02,CNPGL94-07-02, CNPGL 94-49-06, CNPGL 91-25-01, foi estatisticamente superior. O maior valor encontrado para o CNPGL 92-70-02 pode estar relacionado ao fato de que este genótipo apresenta numericamente um dos mais baixos teores de lignina, ou seja, menor lignificação dos constituintes da parede celular vegetal. Além disso, o mesmo genótipo apresentou o menor valor de FDN (Tabela 2) em valor absoluto, acarretando maior fração solúvel do nutriente.

Neste estudo, a fração $\mathrm{A}+\mathrm{B}_{1}$ não diferiu $(\mathrm{P}>0,05)$ entre os cultivares Napier e Cameroon (Tabela 2) e foi menor que a descrita por Malafaia et al. (1998), que encontraram no cultivar Napier cortado aos 60 dias na estação das chuvas $9,9 \%$ de fração $\mathrm{A}+\mathrm{B}_{1}$, fato provavelmente relacionado à estação em que a planta foi cultivada por esses autores, uma vez que a fração solúvel é maior no verão. 
Cabral et al. (2000), em trabalho com capim-elefante, também encontraram maiores valores na fração de carboidratos não-fibrosos no verão, em comparação à primavera, e observaram no cultivar Cameroon cortado aos 63 dias (primavera) 5,54\% de fração de carboidratos não-fibrosos. A fração de CNF determinada neste trabalho foi menor que a encontrada por Lacerda et al. (2004), de $10,06 \%$, em trabalho com capim-elefante cv. Cameroon (capineira) na primavera. No entanto, esses autores avaliaram o cultivar com 2,27 m de altura, ao contrário do ocorrido neste trabalho, quando o capim na época do corte apresentava-se com 1,80 m de altura, o que pode explicar o maior rendimento dos constituintes da parede celular vegetal e, conseqüentemente, o menor valor da fração solúvel (Tabela 2).

A fração B2 variou $(\mathrm{P}<0,05)$ entre os genótipos, obtendo-se os maiores valores com CNPGL 92-94-01, Napier, CNPGL 93-32-02 e Cameroon (Tabela 2). O maior valor numérico encontrado nesta fração no genótipo CNPGL 92-94-01 pode ser explicado pelo fato de que este genótipo apresenta numericamente menor fração $\mathrm{A}+\mathrm{B}_{1}$ e o Cameroon, a menor fração $\mathrm{C}$ em valor absoluto, o que contribuiu para maior porção digestível de FDN. De modo geral, a maior fração $\mathrm{B}_{2}$ encontrada nestes genótipos pode ser explicada pelos seus maiores teores de FDN (Tabela 2). Entre os cultivares Napier e Cameroon, não houve diferença $(\mathrm{P}>0,05)$ na fração $\mathrm{B}_{2}$, apesar de o cultivar Cameroon apresentar numericamente a maior fração. Os valores da fração $B_{2}$ obtidos neste estudo foram superiores aos reportados por Malafaia et al. (1998), que encontraram no capim-elefante, cv. Napier cortado aos 60 dias na estação das chuvas valor da fração $B_{2}$ igual a $69,3 \%$. As condições climáticas onde esses autores conduziram o experimento propiciaram à planta crescimento mais intenso, com maior alongamento do caule e maior deposição de lignina nos tecidos vegetais, ocasionando aumento da fração $\mathrm{C}$ e redução da $\mathrm{B}_{2}$. $\mathrm{O}$ valor da fração $B_{2}$ observado neste estudo foi superior ao relatado por Cabral et al. (2000), que observaram no cultivar Cameroon cortado aos 63 dias (primavera) fração $\mathrm{B}_{2}$ de $68,45 \%$ e da fração $\mathrm{C}$ foi praticamente a metade (Tabela 2), o que resultou em maior porção digestível da FDN. Lacerda et al. (2004), avaliando o mesmo cultivar em sistema de capineira e em mesma estação, encontraram fração $\mathrm{B}_{2}$ de $71,32 \%$, provavelmente em razão do maior teor de lignina $(7,31 \%)$ e da fração $C(18,63 \%)$, que reduziram a fração $B_{2}$.

A fração $C$ também diferiu $(\mathrm{P}<0,05)$ entre os genótipos de capim-elefante. CNPGL 92-94-01, CNPGL 92-70-02, CNPGL 91-06-02, CNPGL 91-25-01, CNPGL 93-32-02 e Cameroon apresentaram as menores frações (Tabela 2). O cultivar Cameroon, por sua vez, apresentou numericamente a menor fração C $(12,48 \%) \mathrm{e}$, ainda, o menor teor de lignina em valor absoluto (Tabela 2). Os genótipos com os menores teores de lignina (Tabela 2) apresentaram conseqüentemente valores mais baixos da fração C (Tabela 2). Malafaia et al. (1998) determinaram no cultivar Napier cortado na estação das chuvas com 60 dias de rebrota valor de 20,8\% para a fração C. Em virtude do desenvolvimento mais intenso da forrageira, verificou-se maior lignificação dos constituintes da parede celular, acarretando maior fração indigerível. Lanna et al. (1996) constataram no cultivar Cameroon avaliado em Piracicaba aos 45 dias de rebrota $4,5 \%$ de fração C. Os maiores valores verificados neste estudo na forrageira cortada aos 56 dias (Tabela 2) estão relacionados à maior lignificação nas células vegetais com o

Tabela 2 - Frações de carboidratos em porcentagem dos carboidratos totais e teores (na matéria seca) de carboidratos não-fibrosos (CNF), fibra em detergente neutro (FDN), lignina e carboidratos totais (CT) de genótipos de capim-elefante

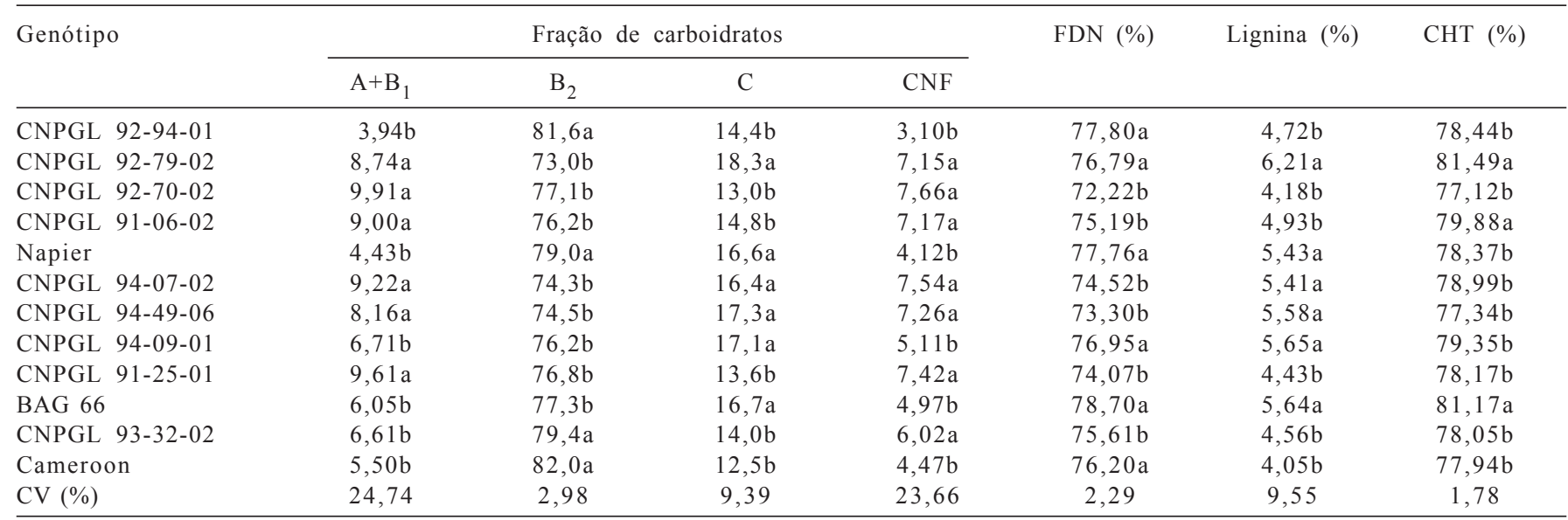


desenvolvimento da planta. $\mathrm{O}$ teor da fração $\mathrm{C}$ do cultivar Cameroon encontrado neste trabalho (Tabela 2) foi superior ao valor $26,01 \%$ obtido por Cabral et al. (2000) quando o cultivar foi cortado aos 63 dias de rebrota, na primavera. Também o teor de lignina (Tabela 2) foi inferior ao valor de $6,38 \%$ relatado por esses autores. Lacerda et al. (2004), em estudo com cultivar Cameroon (capineira, estação-primavera), encontraram na fração C, 18,63\%. O teor de FDN encontrado neste estudo foi semelhante ao relatado por esses autores, porem o teor de lignina obtido $(7,31 \%)$ foi inferior ao apresentado na Tabela 2, contribuindo dessa forma para redução na fração C.

Não foi verificada diferença $(\mathrm{P}>0,05)$ na fração $\mathrm{A}$ dos compostos nitrogenados entre os genótipos de capimelefante. Os genótipos Cameroon e CNPGL 92-79-02 apresentaram numericamente os maiores valores desta fração (Tabela 3), o que pode resultar em crescimento dos microrganismos que fermentam carboidratos estruturais. O genótipo CNPGL 91-25-01, apesar de seu maior maior teor protéico, (Tabela 3), não apresentou numericamente as maiores frações $\mathrm{A}_{\text {e }} \mathrm{B}_{1}$.

A fração obtida no cultivar Napier (Tabela 3) foi superior à descrita por Malafaia et al. (1997) para o capim cortado aos 60 dias no verão, 19,33\% de fração A. Essa diferença pode estar relacionada à época em que foi realizada a avaliação, que promoveu maiores frações $\mathrm{A} \mathrm{e}_{1}$ na forrageira cultivada na primavera (Tabela 3). Lanna et al. (1996) determinaram 13,18\% da fração A para o cultivar Cameroon cortado aos 45 dias de rebrota. Lacerda et al. (2004), avaliando o cultivar Cameroon (capineira) na mesma estação observada neste estudo, verificaram valor de $30,58 \%$ para a fração A.

Apesar de os genótipos não apresentarem diferenças $(\mathrm{P}>0,05)$ quanto à fração $\mathrm{B} 1$, em virtude do elevado coefi- ciente de variação, o CNPGL 91-06-02 apresentou numericamente o maior valor $(6,30 \%)$, o que pode refletir em mais nitrogênio solúvel correspondente a peptídeos e proteína solúvel disponível no rúmen (Tabela 3). Para determinar essa fração, foram realizados vários cálculos, o que certamente resulta no acúmulo de erros nesta fração, gerando um coeficiente de variação superior ao observado nas demais frações. Malafaia et al. (1997) determinaram no cultivar Napier cortado aos 60 dias na estação das chuvas $0,58 \%$ de fração $B_{1}$. Neste estudo, o valor obtido foi quatro vezes maior (Tabela 3 ), provavelmente em razão do crescimento menos intenso da planta na época do cultivo. Lanna et al. (1996) obtiveram no cultivar Cameroon avaliado em Piracicaba aos 45 dias de rebrota $6,59 \%$ de fração $B_{1}$, no entanto, esses autores trabalharam com capim mais tenro. $\mathrm{O}$ valor da fração $\mathrm{B}_{1}$ encontrada neste trabalho (Tabela 3 ) foi bem próximo ao valor 3,52\% relatado por Lacerda et al. (2004), ao avaliarem o cultivar Cameroon em capineira, na estação da primavera.

Os genótipos não apresentaram diferenças $(\mathrm{P}>0,05)$ na fração $B_{2}$. Entretanto, CNPGL 94-49-06, BAG 66 e Napier apresentaram numericamente os maiores valores de nitrogênio insolúvel com taxa intermediária de digestão (Tabela 3). O teor da fração $\mathrm{B}_{2}$ (Tabela 3 ) foi inferior ao relato por Malafaia et al. (1997) para o cultivar Napier cortado na estação das chuvas com 60 dias de rebrota $(43,6 \%)$. O valor da fração $\mathrm{B}_{2}$ no cultivar Cameroon neste estudo (Tabela 3 ) foi inferior ao relatado por Lanna et al. (1996), que determinaram valor de $54,9 \%$ nesse mesmo cultivar com 45 dias de rebrota, no entanto, foi similar ao obtido por Lacerda et al. (2004), que, em trabalho com capim-elefante cultivar Cameroon (capineira) na estação da primavera, obtiveram valor da fração $\mathrm{B}_{2}$ de $34,78 \%$.

Tabela 3 - Frações nitrogenadas, expressas em \% da proteína bruta, e teores na matéria seca de proteína bruta (PB) de genótipos de capim-elefante

\begin{tabular}{|c|c|c|c|c|c|c|}
\hline \multirow[t]{2}{*}{ Genótipo } & \multicolumn{5}{|c|}{ Fração nitrogenada } & \multirow[t]{2}{*}{$\mathrm{PB}(\%)$} \\
\hline & A & $\mathrm{B}_{1}$ & $\mathrm{~B}_{2}$ & $\mathrm{~B}_{3}$ & $\mathrm{C}$ & \\
\hline CNPGL 92-94-01 & $33,0 \mathrm{a}$ & $5,05 \mathrm{a}$ & $37,8 \mathrm{a}$ & $18,5 b$ & $5,68 \mathrm{a}$ & $10,16 \mathrm{a}$ \\
\hline CNPGL 92-79-02 & $39,1 \mathrm{a}$ & $3,48 \mathrm{a}$ & $33,8 \mathrm{a}$ & $17,4 b$ & $6,14 \mathrm{a}$ & $10,30 a$ \\
\hline CNPGL 92-70-02 & $34,7 \mathrm{a}$ & $4,27 \mathrm{a}$ & $36,8 \mathrm{a}$ & $19,6 \mathrm{a}$ & $4,61 b$ & $11,40 \mathrm{a}$ \\
\hline CNPGL 91-06-02 & $36,2 \mathrm{a}$ & $6,30 \mathrm{a}$ & $33,7 \mathrm{a}$ & $17,6 b$ & $6,19 \mathrm{a}$ & $10,56 \mathrm{a}$ \\
\hline Napier & $32,8 \mathrm{a}$ & $2,27 \mathrm{a}$ & $38,3 \mathrm{a}$ & $21,4 \mathrm{a}$ & $5,27 b$ & $10,76 \mathrm{a}$ \\
\hline CNPGL 94-07-02 & $34,0 \mathrm{a}$ & $3,42 \mathrm{a}$ & $36,9 \mathrm{a}$ & $20,7 \mathrm{a}$ & $4,98 b$ & $10,93 \mathrm{a}$ \\
\hline CNPGL 94-49-06 & $35,4 a$ & $4,50 \mathrm{a}$ & $38,7 \mathrm{a}$ & $15,5 b$ & $5,98 \mathrm{a}$ & $10,63 \mathrm{a}$ \\
\hline CNPGL 94-09-01 & $35,0 \mathrm{a}$ & $4,15 \mathrm{a}$ & $35,1 \mathrm{a}$ & $20,2 \mathrm{a}$ & $5,56 \mathrm{a}$ & $11,30 \mathrm{a}$ \\
\hline CNPGL 91-25-01 & $34,3 \mathrm{a}$ & 3,58 a & $34,8 \mathrm{a}$ & $22,7 \mathrm{a}$ & $4,58 b$ & $12,54 \mathrm{a}$ \\
\hline BAG 66 & $35,7 \mathrm{a}$ & $2,02 \mathrm{a}$ & $38,5 \mathrm{a}$ & $17,6 \mathrm{~b}$ & $6,18 \mathrm{a}$ & $10,21 \mathrm{a}$ \\
\hline CNPGL 93-32-02 & $38,0 \mathrm{a}$ & $2,65 \mathrm{a}$ & $34,8 \mathrm{a}$ & $18,8 \mathrm{~b}$ & $5,74 \mathrm{a}$ & $11,12 \mathrm{a}$ \\
\hline Cameroon & $39,2 \mathrm{a}$ & $4,08 \mathrm{a}$ & $33,3 \mathrm{a}$ & $17,1 \mathrm{~b}$ & $6,24 a$ & $10,94 \mathrm{a}$ \\
\hline CV $(\%)$ & 13,82 & 70,64 & 10,02 & 10,88 & 12,08 & 7,54 \\
\hline
\end{tabular}

Médias seguidas de mesma letra não diferem $(P>0,05)$ pelo teste Scott-Knott. 
Os valores da fração $\mathrm{B}_{3}$ diferiram $(\mathrm{P}<0,05)$ entre os genótipos e foram maiores nos cultivares CNPGL 92-70-02, Napier, CNPGL 94-07-02,CNPGL 94-09-01 eCNPGL91-25-01 (Tabela 3), propiciando maior aporte de nitrogênio protéico nos intestinos. Os dados da fração $\mathrm{B}_{3}$ deste estudo foram similares aos obtidos por Malafaia et al. (1997), no cultivar Napier cortado aos 60 dias de idade (estação das chuvas) e um pouco superiores aos encontrados por Lanna et al. (1996), no cultivar Cameroon, de 22,1 e 22,0\%, respectivamente. Também o teor da fração $\mathrm{B}_{3}$ encontrado neste trabalho (Tabela 3 ) foi superior ao valor $13,94 \%$ relatado por Lacerda et al. (2004), em trabalho com o cultivar Cameroon em capineira, na primavera. Uma vez que a planta apresentou, neste trabalho, menor altura $(1,80 \mathrm{~m})$ no momento do corte, houve menor conversão de nitrogênio solúvel para a forma insolúvel $\mathrm{B}_{3}$, associada à parede celular vegetal.

Os genótipos diferiram $(\mathrm{P}<0,05)$ também quanto à fração C, que foi menor nos cultivares CNPGL 92-70-02, Napier, CNPGL 94-07-02 e CNPGL 91-25-01 (Tabela 3). O cultivar Cameroon esteve presente no grupo dos genótipos com maior fração $\mathrm{C}$ e apresentou numericamente o maior valor desta fração, ou seja, $6,24 \%$ da proteína bruta (fração C) contida nesta forrageira não é digerida no trato gastrintestinal, no entanto, esse valor foi inferior ao encontrado por Malafaia et al. (1997), que determinaram no cultivar Napier aos 60 dias de rebrota no período das águas valor de $14,4 \%$ para a fração C. Provavelmente a época em que os autores realizaram o corte colaborou para o aumento desta fração. $\mathrm{O}$ valor da fração $\mathrm{C}$ obtido neste estudo foi superior ao encontrado por Lanna et al. (1996), que obtiveram no cultivar Cameroon em Piracicaba, São Paulo, com 45 dias de rebrota, $3,30 \%$ dessa fração. O menor valor dessa fração deve-se provavelmente ao corte aos 45 dias, que resultou em maior teor das frações $\mathrm{B}_{1}$ e $\mathrm{B}_{2}$. $\mathrm{O}$ valor da fração $C$ da proteína do cultivar Cameroon $(6,24 \%$, Tabela 3$)$ foi inferior a $17,2 \%$, relatado por Lacerda et al. (2004) para este cultivar em capineira na primavera. Essa diferença deve-se, provavelmente, à maior conversão do nitrogênio solúvel para a forma insolúvel $\mathrm{C}$, associada à parede celular vegetal.

\section{Conclusões}

Os genótipos CNPGL 92-70-02 e CNPGL 91-25-01 apresentaram os menores valores de fração $\mathrm{C}$ dos carboidratos totais e, ainda, os menores resultados da fração nitrogenada C, o que acarretou menor fração indigerível do alimento, tornando-se promissores para região norte-fluminense na estação da primavera. No entanto, devem ser realizados mais estudos com outras intensidades de corte e em outras épocas do ano para comprovar a superioridade desses genótipos.

\section{Agradecimento}

À EMBRAPA Gado de Leite, pelo fornecimento dos genótipos de capim-elefante, especialmente ao Dr. Antônio Vander Pereira e ao Dr. Francisco José da Silva Lédo.

\section{Literatura Citada}

ASSOCIATION OF OFFICIAL ANALYTICAL CHEMISTS - AOAC Official methods of analysis. 15.ed. Arlington: 1990. 1117p CABRAL, L.S.; VALADARES FILHO, S.C.; MALAFAIA, P.A.M et al. Frações de carboidratos de alimentos volumosos e suas taxas de degradação estimadas pela técnica de produção de gases. Revista Brasileira de Zootecnia, v.26, n.6, p.2087-2098, 2000 .

EMPRESA BRASILEIRA DE PESQUISA E AGROPECUÁRIA EMBRAPA. Sistema brasileiro de classificação de solos 2.ed. Rio de Janeiro: Embrapa Solos, 2006. 306p.

FERREIRA, D.F. Sistema de análise de variância SISVAR DEX/ UFLA. ver 4.0 (Build 34). Lavras, 1999. 62p.

KRISHNAMOORTHY, U.; MUSCATO, T.V.; SNIFFEN, C.J. et al. Nitrogen fraction in selected feedstuffs. Journal of Dairy Science, v.65, n.1, p.217-225, 1982.

LACERDA, P.D.; MALAFAIA, P.A.M.; VIEIRA, R.A.M. et al. Variação anual da composição bromatológica de duas forrageiras cultivadas nas baixadas litorâneas do Estado do Rio de Janeiro, Brasil. Ciência Rural, v.34, n.2, p.523-529, 2004.

LANNA, D.P.D.; FOX, D.G.; BALSALOBRE, M.A.A. et al Utilização da metodologia de análises de alimentos do CNCPS e do sistema de produção de gás in vitro na estimativa do valor nutricional do capim elefante. In: REUNIÃO ANUAL DA SOCIEDADE BRASILEIRA DE ZOOTECNIA, 33., 1996 , Fortaleza. Anais... Fortaleza: Sociedade Brasileira de Zootecnia, 1996. p.289-291.

LICITRA, G.; HERNANDEZ, T.M.; Van SOEST, P.J. Standardization of procedures for nitrogen fractionation of ruminant feeds. Animal Feed Science and Technology, v.57, p.347-358. 1996.

MALAFAIA, P.A.M.; VALADARES FILHO, S.C.; VIEIRA, R.A.M. et al. Determinação das frações que constituem os carboidratos totais e da cinética ruminal da fibra em detergente neutro de alguns alimentos para ruminantes. Revista Brasileira de Zootecnia, v.27, n.4, p.790-796, 1998.

MALAFAIA, P.A.M.; VALADARES FILHO, S.C.; VIEIRA, R.A.M et al. Determinação e cinética ruminal das frações protéicas de alguns alimentos para ruminantes. Revista Brasileira de Zootecnia, v.26, n.6, p.1243-1251, 1997.

OMETTO, J.C. Bioclimatologia vegetal. São Paulo: Agronômica Ceres Ltda., 1981. 440p.

SNIFFEN, C.J.; O'CONNOR, J.D.; Van SOEST, P.J. et al. A net carbohydrate and protein system for evaluating cattle diets: II. Carbohydrate and protein availability. Journal of Animal Science, v.70, p.3562-3577, 1992.

Van SOEST, P.J., ROBERTSON, J.B. Analysis of forage and fibrous foods. Lab Manual for Animal Science 613. Ithaca: Cornell University, Department of Animal Science, 1985. $202 p$.

Van SOEST, P.J.; ROBERTSON, J.B.; LEWIS, B.A. Methods for dietary fiber, neutral detergent fiber, and nonstarch polysaccharides in relation to animal nutrition. Journal of Dairy Science, v.74, n.10, p.3583-3597, 1991 . 